\title{
Neuropsychological characteristics of preclinical dementia in Parkinson's disease
}

\author{
D.M. Jacobs, PhD; K. Marder, MD, MPH; L.J. Côté, MD; \\ M. Sano, PhD; Y. Stern, PhD; and R. Mayeux, MD, MSE
}

\begin{abstract}
Article abstract-The goal of this study was to characterize the changes in cognition associated with the earliest, or preclinical, stages of dementia in Parkinson's disease (PD). We administered a comprehensive neuropsychological test battery to a group of initially nondemented PD patients participating in a longitudinal community-based epidemiologic study. We used Cox proportional hazards models to assess the relative risk of incident dementia associated with baseline scores on the neuropsychological tests. Baseline performance on two verbal fluency tasks (letter fluency and category fluency) was significantly and independently associated with incident dementia. Tests of memory, orientation, abstract reasoning, naming, and constructional skill were less sensitive predictors of subsequent dementia. The neuropsychological pattern characterizing the preclinical stages of dementia in PD differed from that described previously in preclinical Alzheimer's disease. Results suggest that poor performance on tests of verbal fluency may represent a distinct characteristic of the preclinical phase of dementia in PD.
\end{abstract}

NEUROLOGY 1995;45:1691-1696

Recent reports from several prospective longitudinal studies of aging and dementia have indicated that, in healthy older adults who later develop dementia, neuropsychological tests can detect subtle cognitive changes well before the overt clinical signs of dementia are evident. The stage of the degenerative process prior to the clinical diagnosis of dementia, when only subtle or circumscribed cognitive deficits are evident, has been termed the "preclinical phase" of dementing illness. ${ }^{1}$ Masur et $\mathrm{al}^{2}$ followed 317 initially nondemented participants in the Bronx Aging Study for at least 4 years. Using logistic regression, they found that four measures of cognitive function from the baseline assessment identified one subgroup of subjects with an $85 \%$ probability of developing dementia during the follow-up period and another group with a 95\% probability of remaining dementia-free. Similarly, we examined the associations between baseline neuropsychological test scores and subsequent development of dementia in 443 initially nondemented participants in a community-based, epidemiologic study of dementia in northern Manhattan, NY. ${ }^{3}$ Using Cox proportional hazards models, we found that scores on the Boston Naming Test, ${ }^{4}$ immediate recall on the Selective Reminding Test, ${ }^{5}$ and the Similarities subtest of the Wechsler Adult Intelligence Scale-Revised ${ }^{6}$ were significantly and independently associated with later diagnosis of Alzheimer's disease (AD).

There have been no prospective, longitudinal studies focusing on the neuropsychological manifestations of preclinical dementia in patients with Parkinson's disease (PD). Cross-sectional neuropsychological investigations examining specific domains of cognitive function in PD have indicated that, relative to age-matched normal controls, nondemented patients with PD are impaired on tasks requiring such cognitive abilities as verbal fluency, ${ }^{7 \cdot 13}$ executive functions,,$^{9,14-16}$ visuospatial skills, ${ }^{17-19}$ and recall memory. ${ }^{20,21}$ Longitudinal follow-up of these patients would be useful in illuminating whether these relative impairments remain circumscribed to specific cognitive domains or are early manifestations of dementia. To address this issue, we followed a cohort of initially nondemented PD patients for at least 1 year. We then examined the relative risk of incident dementia associated with scores on neuropsychological tests administered at baseline.

From the Gertrude H. Sergievsky Center (Drs. Jacobs, Marder, Côté, Sano, Stern, and Mayeux) and the Departments of Neurology (Drs. Jacobs, Marder, Côté, Sano, Stern, and Mayeux) and Psychiatry (Drs. Stern and Mayeux), Columbia University College of Physicians and Surgeons; the Center for Alzheimer's Disease Research in the City of New York (Drs. Jacobs, Marder, Côté, Sano, Stern, and Mayeux); and the Division of Epidemiology (Dr. Mayeux), Columbia University School of Public Health, New York, NY.

Supported by federal grants AG07232, AG08702, AG10963, and RR00645 and by the Parkinson's Disease Foundation.

Received November 9, 1994, Accepted in final form February 3, 1995

Address correspondence and reprint requests to Dr. Diane M. Jacobs, Gertrude H. Sergievsky Center, 630 West 168 th Street, New York, NY 10032. 
Methods. Subjects. Data were obtained from subjects participating in a community-based, epidemiologic study of $\mathrm{PD}$ and related disorders in northern Manhattan, NY. Establishment of the cohort has been described in detail elsewhere. ${ }^{22}$ Briefly, subjects were identified through the development of a "registry" for PD and related disorders. Sources of patients included regional hospitals, private practitioners, health maintenance organizations, senior centers, government agencies, and newspaper and radio announcements.

Subjects included in the analyses presented here had completed at least one annual follow-up evaluation in addition to the baseline assessment. Because we were interested in defining the neuropsychological characteristics of preclinical dementia in PD, subjects diagnosed as demented at their initial assessment were excluded from these analyses. In addition, subjects with a history of stroke prior to the baseline assessment were excluded.

Procedures. Subjects were evaluated annually and received the same standardized neurologic and neuropsychological assessment at each study visit. One of three physicians (K.M., L.J.C., or R.M.) conducted a standardized physical and neurologic examination to confirm the diagnosis of PD and recorded each subject's medical history. Idiopathic PD was defined by clinical and research criteria. ${ }^{23-25}$ We excluded patients with secondary parkinsonism resulting from phenothiazines, alphamethyldopa, reserpine, or metaclopramide hydrochloride. $\mathrm{Pa}-$ tients with clinical presentations suggestive of progressive supranuclear palsy, essential tremor, Shy-Drager syndrome, presumed striatonigral degeneration, and olivopontocerebellar atrophy were also excluded. Motor signs and symptoms were rated using the Unified Parkinson's Disease Rating Scale (UPDRS). ${ }^{26}$ Symptoms of depression were rated using the Hamilton Depression Rating Scale. ${ }^{27}$

The neuropsychological battery was designed to be brief yet also to assess a broad range of cognitive functions. Evaluations were conducted in either English or Spanish, based on the subject's primary language and opinion of which language would yield better performance. To assure comparability of evaluations in English and Spanish, all interview questions, test instructions, and stimuli were translated into Spanish and then translated back to ensure accuracy. Specific cognitive functions assessed and neuropsychological tests administered included the following:

Word list learning and memory. The Selective Reminding Test (SRT) ${ }^{5}$ was administered to assess verbal memory. Subjects were given six trials to learn a list of 12 unrelated words. To assess long-term retention of the word list, 15-minute delayed free recall was assessed, followed by a multiple-choice recognition task.

Nonverbal memory. A multiple-choice version of the Benton Visual Retention Test-Form D (BVRT) ${ }^{28}$ was used to assess nonverbal memory. Subjects viewed a geometric design for 10 seconds. It was then removed from view, and the subject was asked to recognize the design in a four-choice multiple-choice array.

Orientation. The 10 orientation items from the MiniMental State Examination (MMSE) ${ }^{29}$ were used to assess orientation to time and place.

Verbal reasoning. The Similarities subtest of the Wechsler Adult Intelligence Scale-Revised (WAIS-R), ${ }^{6}$ which requires subjects to identify relevant similarities or superordinate categories for paired items, was administered.

Nonverbal reasoning. The Identities and Oddities subtest of the Mattis Dementia Rating Scale ${ }^{30}$ was used to assess nonverbal reasoning. In this test, subjects identify which two of three visually presented stimuli are the same. After all eight triads are completed, the same items are administered again, and the subject is required to identify the one item that is different.

Naming. A 15-item version of the Boston Naming Test, ${ }^{4}$ a test of visual confrontation naming, was used to assess word-finding ability.

Letter fluency. Subjects were instructed to generate as many words as possible in 1 minute that began with a given letter of the alphabet, excluding proper nouns and the same word with different suffixes. ${ }^{31}$ English-speaking subjects generated words beginning with the letters C, F, and L, while Spanish-speaking subjects generated words beginning with the letters $\mathrm{P}, \mathrm{S}$, and $\mathrm{V}$. Different letters were used for Spanish- and English-speaking subjects to control for word-frequency differences across the two languages.

Category fluency, All subjects generated exemplars in the categories animals, foods, and clothing; 60 seconds was allowed for each category. For animal fluency, subjects were instructed to name any type of animal but were provided superordinate categories (animals from the farm, jungle, or ocean, or house pets) to assist retrieval. For clothing and food fluency, subjects were instructed to name essentially anything one can wear or eat, respectively.

Auditory comprehension. The first six items of the Complex Ideational Material subtest of the Boston Diagnostic Aphasia Examination ${ }^{32}$ were used to assess comprehension of spoken language.

Repetition. Subjects were asked to repeat the high-frequency phrases from the Boston Diagnostic Aphasia Examination Repetition of Phrases subtest. ${ }^{32}$

Visuoconstructional skills. Subjects copied five designs from the Rosen Drawing Test ${ }^{33}$ ranging in difficulty from simple geometric shapes to overlapping, parallel, and three-dimensional figures.

Visuoperceptual skills. Subjects matched a target design to the same design presented simultaneously in a four-choice multiple-choice array containing the target along with three distractors. Target stimuli corresponded to Form $\mathrm{C}$ of the original BVRT. ${ }^{28}$

Following each evaluation, medical, historical, and neuropsychological data were reviewed at a diagnostic conference of physicians and neuropsychologists, and a consensus diagnosis of presence or absence of dementia was made. The diagnosis of dementia was based on the criteria of the Diagnostic and Statistical Manual of Mental Disorders, revised third edition, ${ }^{34}$ and required evidence of cognitive deficit on the neuropsychological battery as well as evidence of impairment in social or occupational function. Neuropsychological test scores were

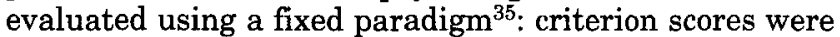
applied to each test score, and subjects performing below these scores on two of three aspects of memory testing (ie, immediate verbal, delayed verbal, or visual memory) plus two other cognitive domains (ie, orientation, language, abstract reasoning, or visuospatial skills) were considered to have sufficient cognitive deficit to meet criteria for dementia. Criterion scores were determined previously based upon a review of the performance of 172 patients and controls who had been evaluated in other studies or in our Memory Disorders Clinic. For each test, mean scores and variability in each group were inspected, and the score that best separated nondemented and demented groups was selected as the criterion score. $^{35}$

Data analysis. We used Cox proportional hazards models ${ }^{36}$ to assess the relative risk (RR) of incident de- 


\begin{tabular}{|c|c|c|c|}
\hline Mean (SD) variable & $\begin{array}{l}\text { Incident } \\
\text { dementia } \\
(\mathbf{N}=\mathbf{2 3})\end{array}$ & $\begin{array}{l}\text { No incident } \\
\text { dementia } \\
(\mathbf{N}=\mathbf{8 8})\end{array}$ & \\
\hline Age & $75.59(8.10)$ & $69.21(11.35)$ & $t=2.53 ; p<0.02$ \\
\hline Education & $10.30(3.72)$ & $11.44(5.02)$ & $t=1.02 ; \mathrm{NS}$ \\
\hline Sex (\% female) & 57 & 43 & $\chi^{2}=1.31 ; \mathrm{NS}$ \\
\hline Language (\% Spanish) & 39 & 39 & $\chi^{2}=0.00 ; \mathrm{NS}$ \\
\hline Duration of Parkinson's disease $(\mathrm{yr})^{*}$ & $8.77(7.38)$ & $6.51(6.80)$ & $t=1.94 ; \mathrm{NS}$ \\
\hline UPDRS & $30.83(13.98)$ & $23.41(11.99)$ & $t=2.55 ; p<0.02$ \\
\hline Hamilton & $8.13(6.06)$ & $5.84(5.07)$ & $t=1.85 ; p<0.07$ \\
\hline Blessed IMC & $5.09(4.00)$ & $4.05(3.80)$ & $t=1.28 ; \mathrm{NS}$ \\
\hline \multicolumn{4}{|c|}{$\begin{aligned} \text { UPDRS } & \text { Unified Parkinson's Disease Rating Scale total sc } \\
\text { Hamilton } & \text { Hamilton Depression Rating Scale total score. } \\
\text { IMC } & \text { Information-Memory-Concentration Test. } \\
\text { NS } & \text { Not significant. } \\
* & \text { Duration of Parkinson's disease from first sympto }\end{aligned}$} \\
\hline
\end{tabular}

mentia associated with baseline scores on the neuropsychological tests. Duration of follow-up was used as the timing variable for Cox analyses. For incident dementia cases with more than one follow-up visit, we used duration from baseline to the first follow-up visit at which dementia was diagnosed; for subjects who remained free of dementia, we used duration from baseline to the last available follow-up visit.

We conducted both exploratory and confirmatory Cox analyses. First, to reduce the large number of candidate variables in the neuropsychological test battery, we performed an exploratory analysis using stepwise Cox regression with backward stepping. Fourteen scores from the baseline neuropsychological assessment competed for retention in the model. The outcome was incident dementia, and the criterion for removal from the model was $p>$ 0.05 . The following variables were included in this initial analysis: total immediate recall, delayed recall, and delayed recognition from the SRT ${ }^{5}$; age-corrected scaled score from the WAIS-R Similarities subtest ${ }^{6}$; total number of words generated across three trials each of letter ${ }^{31}$ and category fluency; and total correct on the Identities and Oddities subtest of the Mattis Dementia Rating Scale, ${ }^{30}$ Rosen Drawing Test, ${ }^{33}$ Benton Visual Retention Test ${ }^{28}$ Matching and Recognition Memory, Boston Naming Test, ${ }^{4}$ Repetition and Auditory Comprehension from the Boston Diagnostic Aphasia Examination, ${ }^{32}$ and the MMSE orientation items. ${ }^{29}$

We then confirmed the usefulness of the variables retained in the stepwise analysis by reexamining them in a Cox regression with simultaneous entry of variates and covariates. In addition to the neuropsychological test scores, age, education, sex, and duration of $\mathrm{PD}$ symptoms were included as covariates. Because our previous investigations have shown that severity of motor signs and depression are significant predictors of incident dementia in PD, ${ }^{37}$ baseline scores on the Hamilton Depression Rating Scale and UPDRS also were included as covariates. All variables were entered into the model simultaneously; thus, the RR associated with each variable was independent of all other variates and covariates.

Results. One hundred twenty-two PD patients who were not demented at the time of their initial assessment had completed at least one follow-up evaluation. Eleven of these patients were excluded from the current analysis because they were missing baseline data for one or more of the following variables: letter fluency $(n=7)$, category fluency $(n=$ 7), Hamilton Depression Rating Scale $(\mathbf{n}=6)$, and UPDRS $(n=1)$. The remaining 111 subjects were included in the Cox models. Twenty-three of the 111 initially nondemented subjects were diagnosed with dementia at follow-up. The average duration of follow-up was $2.70( \pm 1.03)$ years.

Baseline characteristics of subjects who did and did not become demented are presented in table 1 . Subjects who subsequently became demented were older, had more severe motor symptoms, and had more symptoms of depression at baseline than those who did not become demented. The two groups did not differ significantly in education, sex, language spoken, or disease duration. Of note, no significant difference was observed on baseline scores on the Blessed Information-Memory-Concentration Test, ${ }^{38}$ indicating that the two groups were comparable in terms of overall level of cognitive function at the time of initial assessment. The percentage of patients receiving dopamine agonists ( $83 \%$ incident dementia, $75 \%$ no dementia) and anticholinergics (22\% incident dementia, $17 \%$ no dementia) for treatment of PD did not differ between those who did or did not become demented.

Four of the 14 neuropsychological variables in the stepwise Cox regression were retained after backward stepping: total immediate recall on the SRT, category fluency, letter fluency, and Mattis Identities and Oddities. When these four variables were entered simultaneously in a Cox regression along with the covariates (age, education, sex, Hamilton, and UPDRS), the RR of incident dementia associated with baseline scores on letter fluency and category fluency remained significant. Total immediate recall on the SRT and Mattis Identities and Oddities did not contribute significantly to the model that included the covariates. In the final model, letter and category fluency were retained along with the co- 
progression of dementia in $\mathrm{PD}$ compared with $\mathrm{AD}$. Different pathologic substrates may be accounting for the differences in test performance between these subject groups. Results similar to those reported here were observed when we compared nondemented and demented $\mathrm{PD}$ patients with $\mathrm{AD}$ patients ${ }^{41}$; nondemented and demented $P D$ patients performed worse than $\mathrm{AD}$ patients on verbal fluency and visuospatial tasks, even after the PD and $\mathrm{AD}$ groups were equated for overall level of cognitive function. We hypothesize that when dementia occurs in PD, worsening memory is superimposed on cognitive changes that already exist in nondemented patients, but that the dementing process is not due to concomitant $\mathrm{AD}$. As speculated previously ${ }^{39}$ the difficulties with initiating retrieval of information (eg, category exemplars) and generating responses exhibited by PD patients may be due to striatal dysfunction, while the memory, naming, and verbal abstract reasoning deficits in $A D$ patients likely reflect cortical degeneration. There are several possible causes of dementia in PD, however, such as dopamine depletion, cortical Lewy bodies, and cortical cholinergic deficiency with or without $\mathrm{AD}$ pathology. As we have not yet obtained postmortem analyses on the participants in this study, we can conclude only that diminished verbal fluency might be a precursor of any of these conditions.

A potential limitation of the current study is that the tasks within our neuropsychological test battery are not comparable for overall level of difficulty. Thus, variations in test sensitivity may have contributed to the specific profile of deficits that emerged as being predictive of incident dementia. Further, our test battery does not include formal measures of "executive function" on which nondemented patients with $\mathrm{PD}$ often perform poorly, such as the Wisconsin Card Sorting Test, ${ }^{42}$ the Stroop Test, ${ }^{43}$ or the Trail Making Test. ${ }^{44}$ These tests might have detected additional subtle cognitive changes in our nondemented PD patients who subsequently became demented and might have provided a further independent contribution to the prediction of incident dementia. As noted above, we hypothesize that the poor performance of some PD patients on our tests of verbal fluency reflects executive dysfunction.

In summary, the current study provides evidence of a preclinical phase in the dementia of $P D$ and suggests that the neuropsychological characteristics of predementia in PD are distinct from those previously reported to be associated with preclinical AD. The divergent cognitive profiles between $\mathrm{PD}$ and $\mathrm{AD}$ patients may reflect different pathologic substrates for the dementia syndromes associated with these two diseases.

\section{Acknowledgments}

The authors wish to thank Ms. Brenda Alfaro and Ms. Helen Mejia for their assistance in coordinating this project, Dr. MingXin Tang for statistical support, and two anonymous reviewers for their helpful comments.

\section{References}

1. Aronson MK, Ooi WL, Morgenstern H, et al. Women, myocardial infarction, and dementia in the very old. Neurology 1990;40:1102-1106.

2. Masur DM, Sliwinski M, Lipton RB, Blau AD, Crystal HA. Neuropsychological prediction of dementia and absence of dementia in healthy elderly persons. Neurology 1994;44: 1427-1432.

3. Jacobs DM, Sano M, Dooneief G, Marder K, Bell KL, Stern $\mathrm{Y}$. Neuropsychological detection and characterization of preclinical Alzheimer's disease. Neurology 1995;45:957-962.

4. Kaplan E, Goodglass H, Weintraub S. Boston naming test. Philadelphia: Lea \& Febiger, 1983.

5. Buschke H, Fuld PA. Evaluating storage, retention, and retrieval in disordered memory and learning. Neurology 1974; 24:1019-1025.

6. Wechsler D. Wechsler adult intelligence scale-revised. New York: Psychological Corporation, 1981.

7. Bayles KA, Trosset MW, Tomoeda CK, Montgomery EB Jr, Wilson J. Generative naming in Parkinson disease patients. J Clin Exp Neuropsychol 1993;15:547-562.

8. Globus M, Mildworf B, Melamed E. Cerebral blood flow and cognitive impairment in Parkinson's disease. Neurology 1985;35:1135-1139.

9. Lees AJ, Smith E. Cognitive deficits in the early stages of Parkinson's disease. Brain 1983;106:257-270.

10. Matison R, Mayeux R, Rosen J, Fahn S. 'Tip-of-the-tongue' phenomenon in Parkinson's disease. Neurology 1982;32:567570 .

11. Auriacombe S, Grossman M, Carvell S, Gollomp S, Stern MB, Hurtig HI. Verbal fluency deficits in Parkinson's disease. Neuropsychology 1993;7:182-192.

12. Gurd JM, Ward CD. Retrieval from semantic and letter-initial categories in patients with Parkinson's disease. Neuropsychologia 1989;27:743-746.

13. Raskin SA, Sliwinski M, Borod JC. Clustering strategies on tasks of verbal fluency in Parkinson's disease. Neuropsychologia 1992;30:95-99.

14. Brown RG, Marsden CD. Internal versus external cues and the control of attention in Parkinson's disease. Brain 1988; 111:323-345.

15. Flowers KA, Robertson C. The effects of Parkinson's disease on the ability to maintain a mental set. J Neurol Neurosurg Psychiatry 1985;48:517-529.

16. Levin BE, Llabre MM, Weiner WJ. Cognitive impairments associated with early Parkinson's disease. Neurology 1989; 39:557-561.

17. Proctor F, Riklan M, Cooper ST, Teuber HL. Judgment of visual and postural vertical by parkinsonism patients. Neurology $1964 ; 14: 287-293$.

18. Villardita C, Smirni P, LaPira F, Zappala G, Nicoletti F. Mental deterioration, visuoperceptive disabilities and constructional apraxia in Parkinson's disease. Acta Neurol Scand 1982;66:112-120.

19. Levin BE, Llabre MM, Reisman S, et al. Visuospatial impairment in Parkinson's disease. Neurology 1991;41:365369.

20. Weingartner H, Burns S, Diebel R, Lewitt PA. Cognitive impairment in Parkinson's disease: distinguishing between effort-demanding and autonomic cognitive processes. Psychiatry Res 1984;11:223-235.

21. El-Awar M, Becker JT, Hammond KM, Nebes RD, Boller F. Learning deficits in Parkinson's disease: comparison with Alzheimer's disease and normal aging. Arch Neurol 1987;44:180-184.

22. Mayeux R, Denaro J, Hemenegildo N, et al. A populationbased investigation of Parkinson's disease with and without dementia: relationship to age and gender. Arch Neurol 1992; 49:492-497.

23. Ward CD, Gibb WR. Research diagnostic criteria for Parkinson's disease. In: Streiffler MB, Korczyn AD, Melamed E, Youdim MB, eds. Parkinson's disease: anatomy, pathology and therapy. New York: Raven Press, 1990:245-249.

24. Hughes AJ, Daniel SE, Kilford L, Lees AJ. Accuracy of clinical diagnosis of idiopathic Parkinson's disease: a clinico- 
pathological study of 100 cases. J Neurol Neurosurg Psychiatry 1992;55:181-184.

25. Hughes A.J, Ben-Shlomo Y, Daniel SE, Lees AJ. What features improve the accuracy of clinical diagnosis in Parkinson's disease: a clinicopathologic study. Neurology 1992;42: 1142-1146.

26. Stern MB, Hurtig HI. The clinical characteristics of Parkinson's disease and Parkinsonian syndromes: diagnosis and assessment. In: The comprehensive management of Parkinson's disease. New York: PMA Corp, 1978:3-50.

27. Williams JB. A structured interview guide for the Hamilton Depression Rating Scale. Arch Gen Psychiatry 1988;45:742747.

28. Benton AL. The visual retention test. New York: Psychological Corporation, 1955.

29. Folstein MF, Folstein SE, McHugh PR. 'Mini-mental state.' A practical method for grading the cognitive state of patients for the clinician. J Psychiatr Res 1975;12:189-198.

30. Mattis S. Mental status examination for organic mental syndrome in the elderly patient. In: Bellak L, Karasu TB, eds. Geriatric psychiatry. New York: Grune \& Stratton, 1976:77. 121.

31. Benton AL, Hamsher KdeS. Multilingual aphasia examination. Iowa City: University of Iowa, 1976.

32. Goodglass H, Kaplan E. The assessment of aphasia and related disorders. 2nd ed. Philadelphia: Lea \& Febiger, 1983.

33. Rosen W. The Rosen drawing test. Bronx, NY: Veterans Administration Medical Center, 1981.

34. American Psychiatric Association. Diagnostic and statistical manual of mental disorders. 3rd ed, rev. Washington, DC:
American Psychiatric Association Press, 1987.

35. Stern Y, Andrews H, Pittman J, et al. Diagnosis of dementia in a heterogeneous population: development of a neuropsychological paradigm-based diagnosis of dementia and quantified correction for the effects of education. Arch Neurol 1992;49:453-460.

36. Cox DR. Regression models and life-tables. J R Stat Soc 1972;34:187-220.

37. Marder K, Tang M-X, Cote L, Stern Y, Mayeux R. The frequency and associated risk factors for dementia in patients with Parkinson's disease. Arch Neurol (in press).

38. Blessed G, Tomlinson BE, Roth M. The association between quantitative measures of senile change in the cerebral grey matter of elderly subjects. Br J Psychol 1968;114:797-811.

39. Randolph C, Braun AR, Goldberg TE, Chase TN. Semantic fluency in Alzheimer's, Parkinson's, and Huntington's disease: dissociation of storage and retrieval failures. Neuropsychology 1993;7:82-88.

40. Beatty WW, Monson N, Goodkin E. Access to semantic memory in Parkinson's disease and multiple sclerosis. J Geriatr Psychiatry Neurol 1989;2:153-162.

41. Stern Y, Richards M, Sano M, Mayeux R. Comparison of cognitive changes in patients with Alzheimer's and Parkinson's disease. Arch Neurol 1993;50:1040-1045.

42. Berg EA. A simple objective test for measuring flexibility in thinking. J Gen Psychol 1948;39:15-22.

43. Stroop JR. Studies of interference in serial verbal reactions. J Exp Psychol 1935;18:643-662.

44. Reitan R. Validity of the Trail Making Test as an indicator of organic brain damage. Percept Mot Skills 1958;8:271-276.

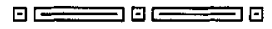 \\ Emotional facial imagery, perception, and expression in Parkinson's disease
}

\author{
Daniel H. Jacobs, MD; Jeffrey Shuren, MD; Dawn Bowers, PhD; and Kenneth M. Heilman, MD
}

\begin{abstract}
Article abstract-Patients with Parkinson's disease (PD) may be impaired at expressing emotional faces and perceiving emotional facial affect. We tested the hypothesis that patients with PD may be impaired at imaging emotional faces. We first compared 12 patients with PD and 30 control subjects on perceptual and imagery tasks. Patients were significantly impaired on a task of emotional facial imagery but not on a control task of object imagery. Patients were also impaired on a task of perceiving emotional faces. Subsequently, we found that PD patients were impaired relative to controls on making emotional faces. Performance on both the perceptual and motor tasks of facial expression significantly correlated with performance on the emotional facial imagery task. We suggest that the basal ganglia, together with the right hemisphere, are part of a neural network subserving emotional facial tasks.
\end{abstract}

NEUROLOGY 1995;45:1696-1702

The formation of mental images is assumed to depend upon accessing long-term memory stores from visual cortical representations., ${ }^{1,2}$ Initially, Farah ${ }^{1}$ proposed that visual representations, used both for imagery and for perception, were housed in the posterior left hemisphere. However, dissociations

From the Department of Neurology, University of Florida College of Medicine, and the Veterans Administration Medical Center, Gainesville, FL.

Supported by the Memory Disorders Clinics, Department of Elder Affairs of the State of Florida; the Department of Veterans Affairs Research Service; and grant RO1MH48861.

Received November 1, 1994. Accepted in final form February 3, 1995.

Address correspondence and reprint requests to Dr. Daniel H. Jacobs, Department of Neurology, New England Medical Center, 750 Washington Street, Boston, MA 02111. 


\section{Neurology}

\section{Neuropsychological characteristics of preclinical dementia in Parkinson's disease}

D. M. Jacobs, K. Marder, L. J. Cote, et al.

Neurology 1995;45;1691-1696

DOI 10.1212/WNL.45.9.1691

\section{This information is current as of September 1,1995}

\section{Updated Information \& Services}

\section{References}

Citations

Permissions \& Licensing

Reprints including high resolution figures, can be found at: http://n.neurology.org/content/45/9/1691.full.html

This article cites 33 articles, 3 of which you can access for free at: http://n.neurology.org/content/45/9/1691.full.html\#\#ref-list-1

This article has been cited by 13 HighWire-hosted articles: http://n.neurology.org/content/45/9/1691.full.html\#\#otherarticles

Information about reproducing this article in parts (figures,tables) or in its entirety can be found online at: http://n.neurology.org/misc/about.xhtml\#permissions

Information about ordering reprints can be found online: http://n.neurology.org/misc/addir.xhtml\#reprintsus

Neurology $®$ is the official journal of the American Academy of Neurology. Published continuously since 1951, it is now a weekly with 48 issues per year. Copyright Copyright 1995 by Advanstar Communications Inc.. All rights reserved. Print ISSN: 0028-3878. Online ISSN: 1526-632X.

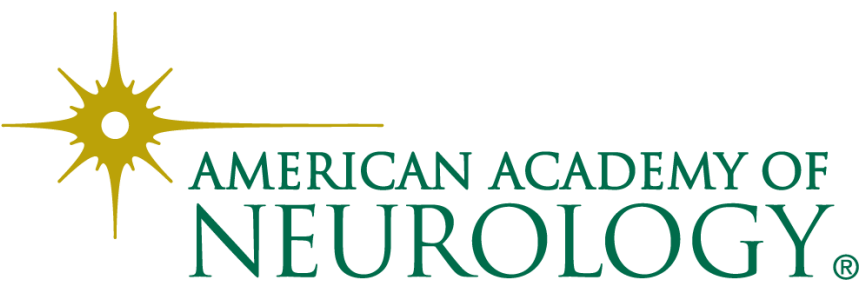

